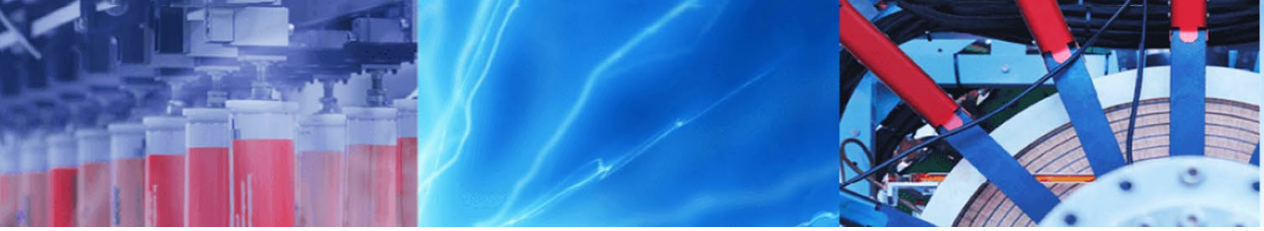

Research Article

\title{
Highly microstructured porous carbon derived from vitex mombassae for high specific capacitance supercapacitors
}

\author{
Talam Enock Kibona ${ }^{1}$ \\ () Springer Nature Switzerland AG 2019
}

\begin{abstract}
This study reports on producing highly porous carbon materials by carbonization and activation of biomass (Vitex mombassae) seed wastes. The pore textural properties and microstructures of the synthesized materials are controlled by adjusting the activation temperature from 600 to $800^{\circ} \mathrm{C}$. X-ray diffraction, scanning electron microscopy, X-ray photoelectron spectroscopy, transmission electron microscopy, Raman and nitrogen adsorption and desorption are used to study the physical characteristics of the synthesized materials. The Brunauer-Emmet-Teller surface area, micropore surface area and pore volume increase with activation temperature. At activation temperature of $700{ }^{\circ} \mathrm{C}$, the porous carbon acquires high specific area $\left(2044 \mathrm{~m}^{2} \mathrm{~g}^{-1}\right)$. The pore volume increases with increase in activation temperature $0.8-1.1 \mathrm{~cm}^{3} \mathrm{~g}^{-1}$ with high self-doping oxygen content. As a result of good physical characteristics, the prepared electrodes exhibit excellent performance with the specific capacitance up to $437 \mathrm{~F} \mathrm{~g}^{-1}$ at $5 \mathrm{mV} \mathrm{s}^{-1}$ in $6 \mathrm{M} \mathrm{KOH}$ electrolyte. The good capacitive behavior of the synthesized porous carbon depends on high surface area, micropore pore volume as well as moderate microstructures. The synthesized sample demonstrates high cyclic stability with capacitance retention of over $90 \%$ after 50,000 cycles.
\end{abstract}

Keywords Porous carbon · Vitex mombassae · Specific capacitance and supercapacitors

\section{Introduction}

Over the past years, supercapacitors hold the promise of energy storage in various applications due to their long life span and high power density [1]. These properties suggest a range of applications of supercapacitors which include high-power delivery system, backup power sources in electric vehicles, electronic devices, few to mention [2]. However, their applications are hampered by their low energy densities, and thus, researchers are trying to improve the energy density by increasing specific capacitances.

Energy storage in supercapacitors can be characterized as electric double-layer energy storage mechanism or pseudocapacitance mechanism. The electric double-layer energy storage mechanism requires high surface area and well-structured pores for high specific energy storage. However, developing high surface area and highly porous carbon remains a challenge. To defeat the aforesaid challenge, efforts have been made by synthesizing porous carbon from biomasses, especially agriculture wastes such as bamboo shoot shells, biogas slurry, orange peels, concorb and others [3-9]. The interest in biomass-based supercapacitor electrodes is catalyzed by the exciting properties (long life cycle, low cost, deformability and high specific capacitance) [10]. The focus has been synthesizing porous materials with high surface area, interconnected pores and pore sizes that will allow the formation of carbon/ electrolyte double-layer interface for increasing specific capacitance.

Biomass-derived porous carbon materials have been reported to be synthesized through hydrothermal

Talam Enock Kibona, kibona@muce.ac.tz| ${ }^{1}$ Department of Mathematics, Physics and Informatics, Mkwawa University College of Education, University of Dar es Salaam, P.O. Box 2513, Iringa, Tanzania.

SN Applied Sciences (2019) 1:1095 | https://doi.org/10.1007/s42452-019-1125-9

Received: 30 June 2019 / Accepted: 21 August 2019 / Published online: 26 August 2019 
carbonization [11-13], direct carbonization followed by activation [14-18], soft and hard template carbonization [19-21] and molten salt carbonization [22-24]. Of the aforementioned routes, direct carbonization followed by activation has gained more attention because it increases the surface area of the porous carbon and easily adjusts the mesopores to micropores which plays an important role in energy storage.

Vitex mombassae plants are well grown in woodland, especially in Tanzania Zimbabwe and South Africa. Vitex mombassae produces fruits which are eaten as wild fruits [25], and they are used to prepare jam; however, their seeds are discarded as wastes. This study utilized the vitex mombassae seed waste as carbon precursor for synthesizing high surface area nanomaterials. The high surface area, microstructured and highly pore textured porous materials are obtained through varying activation temperature from 600 to $800^{\circ} \mathrm{C}$. The fabricated electrodes demonstrate a high gravimetric capacitance of about $437 \mathrm{~F} \mathrm{~g}^{-1}$ at a scan rate of $5 \mathrm{mV} \mathrm{s}^{-1}$ in $6 \mathrm{M} \mathrm{KOH}$ electrolyte.

\section{Experimental sections}

\subsection{Materials}

Vitex mombassae (VM) fruits wastes were collected from Iringa Tanzania. Potassium hydroxide and hydrochloric acids were purchased from Sigma-Aldrich. Polyvinylidene difluoride (PVDF), conducting carbon and $\mathrm{N}$-methyl pyrrolidone were purchased from MTI Corporation. All chemicals were used without further purification.

\subsection{Synthesis of activated carbon}

The VM seed wastes were collected in large amount, washed and dried in air for 1 week. Dried VM seed wastes were then crushed into small particles of around $160 \mu \mathrm{m}$. The crushed VM seed waste particles were put into alumina boat crucible and carbonized in horizontal tube furnace (CTF12/65/550) from Carbolite, UK, at $450^{\circ} \mathrm{C}$ for $1 \mathrm{~h}$ in nitrogen atmosphere at a heating rate of $5^{\circ} \mathrm{C} / \mathrm{min}$. The carbonized VM seeds were further activated with $\mathrm{KOH}$ at carbon-to- $\mathrm{KOH}$ mass ratio of 1:3 which has been reported to be optimal mixing ratio for many biomass carbon precursors $[4,26]$. The mixtures were activated at 600,700 and $800^{\circ} \mathrm{C}$ for $2 \mathrm{~h}$ in nitrogen atmosphere at the heating rate of $5^{\circ} \mathrm{C} \mathrm{min}{ }^{-1}$. The tube furnace was left to cool naturally to room temperature, and then, activated carbon was taken out. The final products were then washed with $1 \mathrm{M} \mathrm{HCl}$ and sufficient distilled water in order to remove other organics. The samples were designated as VM- $T$ with $T$ representing the activation temperature, whereas the unactivated sample was designated as VM.

\subsection{Characterizations of activated carbon}

FLASH 2000 Organic Elemental Analyzer, Thermo Scientific, was used to study the bulk elemental compositions of the samples. Sorption studies of the samples were performed using Quantachrome Autosorb iQ instrument using nitrogen gas sorption at $77.35 \mathrm{~K}$. All samples were degassing at $200^{\circ} \mathrm{C}$ for $5 \mathrm{~h}$ prior to the adsorption experiments in order to eliminate the surface gaseous contaminants. The BET surface area was calculated using the Brunauer-Emmet-Teller (BET) equation. The external surface area, micropore surface area and pore volume were determined through $t$ plot method. The pore size distributions were calculated from nitrogen adsorption branch using nonlocal density functional theory (NLDFT) adsorption branch model. Scanning electron microscope (FEI Nova NanoSEM 450) with an accelerating voltage of 15 $\mathrm{kV}$ having a beam current of $2.0 \mathrm{~mA}$, magnification capability of 100,000 and working distance of $14,800 \mu \mathrm{m}$ was used to observe the microscopic surface morphology of the samples. The X-ray spectrophotometer spectra (XPS) were studied through PHI model Quantum 2000 spectrometer using $\mathrm{Al} \mathrm{Ka}$ radiation as the radiation source with wavelength $(\lambda=1486.6 \mathrm{eV})$. The microstructure of the materials was obtained using high-resolution transition electron microscope (Talos F200X microscope) operated at voltage of $200 \mathrm{kV}$. The diffraction pattern of the materials was identified through powder X-ray diffractometer (PXRD) performed on Rigaku Ultima IV diffractometer (Cu Ka radiation, $\lambda=1.5406 \AA$ ) with acceleration voltage and current of $40 \mathrm{kV}$ and $44 \mathrm{~mA}$, respectively. The diffraction patterns were obtained in the step scanning of $0.02\left(2 \theta^{\circ}\right)$ in the range of $5<\left(2 \theta^{\circ}\right)<75$.

\subsection{Electrode preparation and electrochemical measurements}

The electrochemical measurements were performed using PGSTAT204 Autolab workstation (Metrohm). The working electrodes were prepared by mixing VM porous carbon, conducting carbon and polyvinylidene fluoride (PVDF) (in N-methylpyrrolidone) in the weight ratio of 80:10:10. The working electrodes were pressed in a nickel foam and dried at $100^{\circ} \mathrm{C}$ for $10 \mathrm{~h} . \mathrm{Ag} / \mathrm{AgCl}$ and platinum wire were used as reference and counter electrodes, respectively. Cyclic voltammetry (CV) measurements were conducted in the voltage range of -1.0 to $0.0 \mathrm{~V}$ at a scan rate of 5 , to $200 \mathrm{mV} \mathrm{s}^{-1}$. Electrochemical impedance spectroscopy (EIS) measurements were taken in a frequency range of $1 \mathrm{mHz}$ 
to $1 \mathrm{MHz}$. The specific capacitance was calculated from CV using Eq. (1):

$C=\frac{1}{2 m v\left(E_{2}-E_{1}\right)} \int_{E_{1}}^{E_{2}} i(E) \mathrm{d} E$

where $\left(E_{2}-E_{1}\right)$ is the applied potential window, $m(\mathrm{~g})$ is the weight of the active material, $v\left(\mathrm{mV} \mathrm{s}^{-1}\right)$ is the scan rate and $\int_{V 1}^{V 2} i(V) \mathrm{d} V$ is the total voltammetric charge obtained

Table 1 Bulk elemental compositions of the samples

\begin{tabular}{llll}
\hline Sample & $\mathrm{C}$ & $\mathrm{H}$ & $\mathrm{O}$ \\
\hline $\begin{array}{l}\text { Raw } \\
\text { (uncar- } \\
\text { bonized) }\end{array}$ & 45.1 & 5.9 & 34.4 \\
VM & 74.7 & 3.0 & 8.4 \\
VM-600 & 86.8 & 2.6 & 5.3 \\
VM-700 & 83.9 & 1.8 & 2.8 \\
VM-800 & 66.6 & 1.3 & 12.0 \\
\hline
\end{tabular}

by integration of negative and positive sweeps in cyclic voltammograms.

\section{Results and discussion}

\subsection{Elemental composition}

In order to qualify VM for supercapacitors application, bulk elemental compositions of the raw and carbonized samples were studied using CHNOs elemental analyzer. It can be seen in Table 1 that the quantities of carbon are $45 \%, 75 \%, 87 \% 84 \%$ and $67 \%$ for raw (uncarbonized), VM, VM600, VM700 and VM800, respectively. The carbon content in the samples decreased with activation temperature from $87 \%$ at $600{ }^{\circ} \mathrm{C}$ to $67 \%$ at $800^{\circ} \mathrm{C}$. The percentage of carbon in the samples qualifies VM for supercapacitor application.

Sorption studies of the prepared samples as done through $\mathrm{N}_{2}$ adsorption and desorption are shown in Fig. 1. The unactivated sample clearly shows type IV isotherms which demonstrate the presence of mesopores
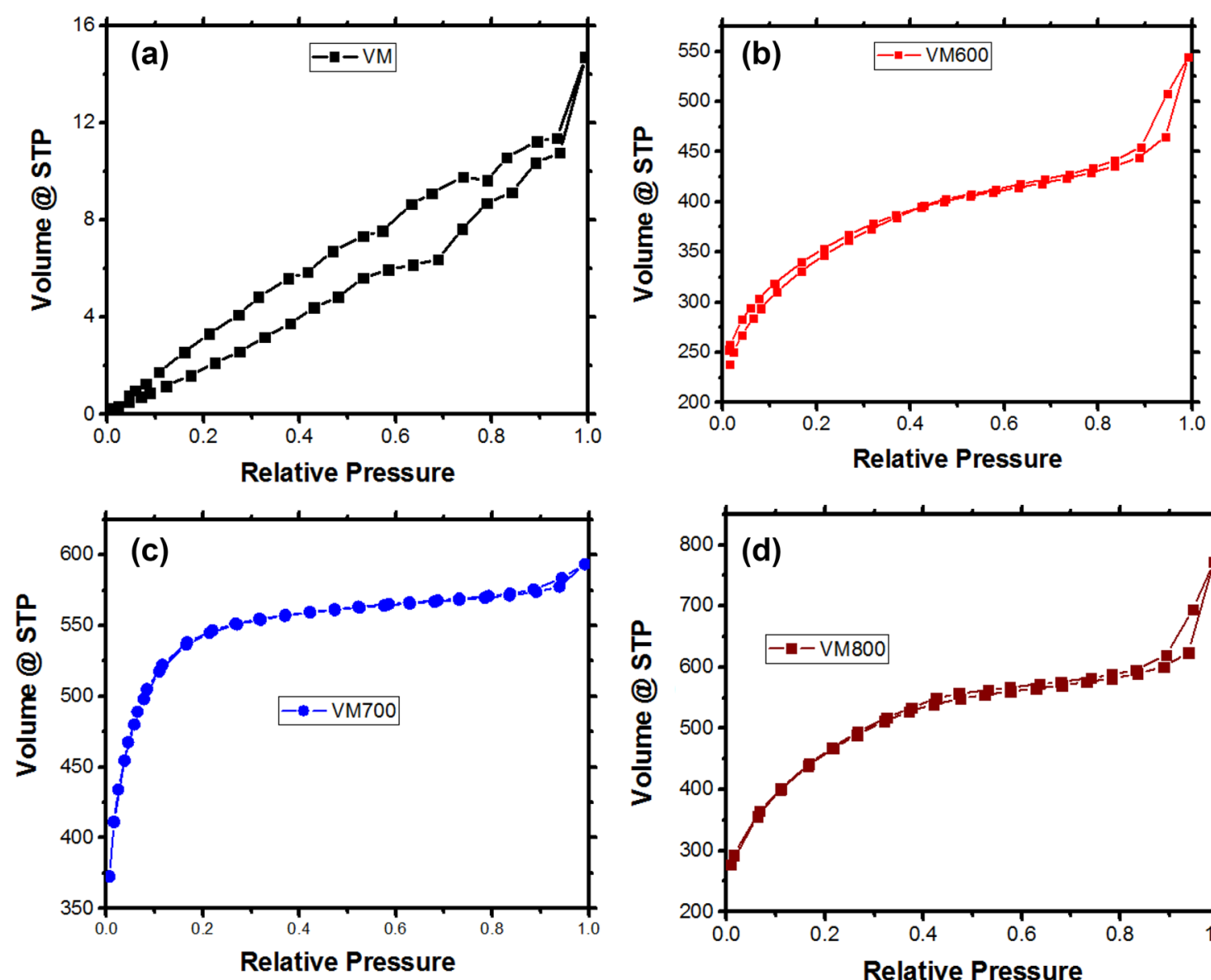

Fig. 1 Nitrogen adsorption-desorption curves of a VM, b VM600, c VM700, d VM800 
(Fig. 1a). As the activation temperature increased, the isotherms of VM600, VM700 and VM800 demonstrated overwhelmingly microporous textures with the coexistence of mesopores with hysteresis loop type IV (Fig. $1 \mathrm{~b}-\mathrm{d}$ ). Figure 2 shows the pore size distribution of the synthesized samples. From Fig. 2a, b, it is observed that all samples (except VM) exhibited a combination of mesopores and micropores. As shown in Fig. 2b, the micropores are centered at 1.5 and $2 \mathrm{~nm}$ while the mesopores are centered between 2 and 4.5 as well as between 30 and $40 \mathrm{~nm}$ as evidenced in Fig. 2a, b, respectively. The combination of micropores and mesopores in the synthesized porous materials is beneficial to energy storage as it is accepted that the mesoporous structure can improve the charge transfer while micropores have high surface area which in turn offer more active sites for charge adsorption and hence increase specific capacitance.
The influence of activation temperature on BET, micropore and mesopore surface areas, pore size and total pore volume is depicted in Table 2. The specific surface area as calculated by Brauner-Emmet-Teller (BET) method was found to be 14, 1253, 2044 and $1622 \mathrm{~m}^{2} \mathrm{~g}^{-1}$ for VM, VM600, VM700 and VM800, respectively. It can be noted that increasing activation temperature from 600 to $700{ }^{\circ} \mathrm{C}$, the BET surface area was increased by $790 \mathrm{~m}^{2} \mathrm{~g}^{-1}$. When the activation temperature was further altered to $800{ }^{\circ} \mathrm{C}$, the BET surface area was decreased by $422 \mathrm{~m}^{2} \mathrm{~g}^{-1}$. It can be stretched that as the activation temperature was increased from 600 to 700 , the reaction rate between $\mathrm{C}$ and $\mathrm{KOH}$ increased which in turn increased carbon burn-off. Similarly, the devolatilization process of the carbon chars increased with activation temperature to produce more pores from the carbon chars. Carbon burn-off and evolvement of volatiles increase BET surface area. However, at high
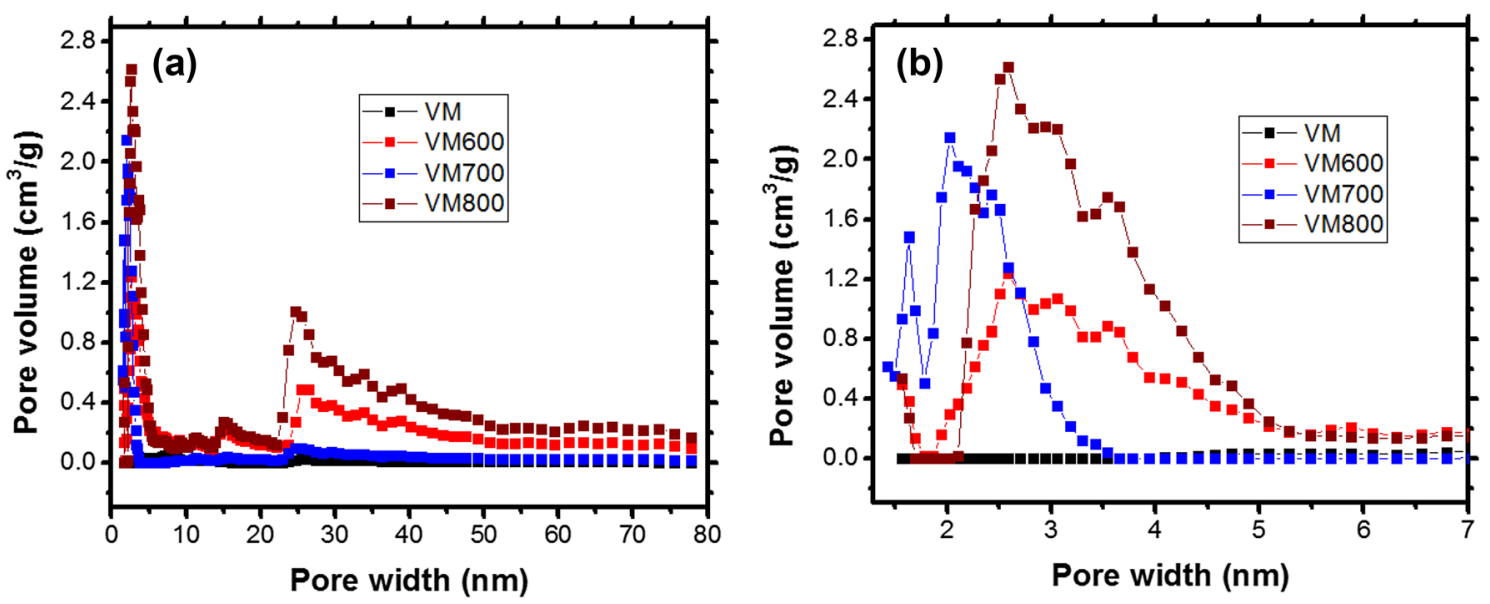

Fig. 2 Pore size distribution: a pore width $0-80 \mathrm{~nm}$, b pore width $0-7 \mathrm{~nm}$

Table 2 Textural properties of synthesized samples

\begin{tabular}{lccccccccc}
\hline Sample & $S_{\text {BET }}\left(\mathrm{m}^{2} \mathrm{~g}^{-1}\right)^{\mathrm{a}}$ & $S_{\text {micro }}\left(\mathrm{m}^{2} \mathrm{~g}^{-1}\right)^{\mathrm{b}}$ & $S_{\text {meso }}\left(\mathrm{m}^{2} \mathrm{~g}^{-1}\right)^{\mathrm{c}}$ & $S_{\text {micro }} / S_{\text {meso }}$ & $\begin{array}{l}V_{\text {micro }} \\
\left(\mathrm{cm}^{3} \mathrm{~g}^{-1}\right)^{\mathrm{d}}\end{array}$ & $\begin{array}{l}V_{\text {meso }} \\
\left(\mathrm{cm}^{3} \mathrm{~g}^{-1}\right)^{\mathrm{e}}\end{array}$ & $V_{\text {micro }} / V_{\text {meso }}$ & $V_{\mathrm{T}}\left(\mathrm{cm}^{3} \mathrm{~g}^{-1}\right)^{\mathrm{f}}$ & $D_{\text {Average }}(\mathrm{nm})^{\mathrm{g}}$ \\
\hline VM & 14 & 2.4 & 11.6 & 0.2 & 0.0 & & 0 & 0 & 2 \\
VM600 & 1254.6 & 977.5 & 277 & 3.5 & 0.4 & 0.4 & 1 & 0.8 & 2.6 \\
VM700 & 2043.8 & 1945.8 & 98 & 5.0 & 0.9 & 0.8 & 8 & 1.7 & 2 \\
VM800 & 1622.1 & 1171.2 & 450.9 & 2.8 & 1.1 & 0.5 & 0.6 & 2.6 & 2.6 \\
\hline
\end{tabular}

${ }^{\mathrm{a} B E T}$ surface area

${ }^{\mathrm{b}}$ Micropore surface area

${ }^{c}$ Mesopore surface area

${ }^{\mathrm{d}}$ Micropore volume

eMesopore volume

${ }^{\mathrm{f}}$ Total pore volume

${ }^{9}$ Average pore size 
activation temperature $\left(800^{\circ} \mathrm{C}\right)$, the BET surface area decreased because of excessive carbon burn-off which resulted into pores widening and collapse of the pores and loss of walls, hence limiting the BET surface area [27]. The micropore surface area $\left(S_{\text {micro }}\right)$ increased with activating temperature and reached its optimal value at $700{ }^{\circ} \mathrm{C}$ and then decreased at higher temperature $800^{\circ} \mathrm{C}$. On the other hand, mesopore surface area $\left(S_{\text {meso }}\right)$ decreased with increasing activation temperature and increased at higher temperature as depicted in Table 2. The contribution of micropore surface area in percentage $\left(S_{\text {micro }} / \mathrm{BET}\right)$ was $17,78,95$ and $72 \%$ for VM, VM600, VM700 and VM800, respectively. VM700 exhibited high Smicro $1945.8 \mathrm{~m}^{2} \mathrm{~g}^{-1}$ and up to $95 \%$ micropore surface area and $89 \%$ micropore volume. It can be seen further that the total pore volume increased with activation temperature. At $600^{\circ} \mathrm{C}$ activation temperature, the mesopore and micropore volume was $50 \%$ each. The ratio between micropore surface area and mesopore surface area $\left(S_{\text {micro }} / S_{\text {meso }}\right)$ corresponds well with the ratio between micropore to mesopore volumes $\left(V_{\text {micro }} / V_{\text {meso }}\right)$ which is the highest at activating temperature of $700^{\circ} \mathrm{C}$.
The morphologies of the synthesized porous materials derived from VMs are shown in Fig. 3. It can be seen that the morphologies are dependent on the activation temperature. At $700{ }^{\circ} \mathrm{C}$ and $800{ }^{\circ} \mathrm{C}$, the morphologies of the samples acquired the cylindrical structures of the pores. The developed pore structures in Fig. 3b-d may have resulted due to introduction of $\mathrm{KOH}$ which break down the cellulosic and lignin structure of the VM seeds into microstructures by burning more carbon to produce pores. For VM600-VM700, the pores developed are vividly shown to be qualifying the materials for energy storage usage. The formation of pores was further confirmed in TEM image (Fig. 4a-b). The existence of these pores is important for charge transfer in energy storage devices.

Figure 5a shows XRD patterns for VM and VM700 as representative samples. It can be seen that all samples show two broad peaks at around $2 \theta=24^{\circ}$ and $42^{\circ}$ indexed to (200) and (100) plane of reflection, respectively. The peak at $2 \theta=24^{\circ}$ is more pronounced in VM than VM700 while at $2 \theta=42$, VM700 had more pronounced peak than VM. The presence of strong background at low angle for the synthesized samples signifies that the rich micropores
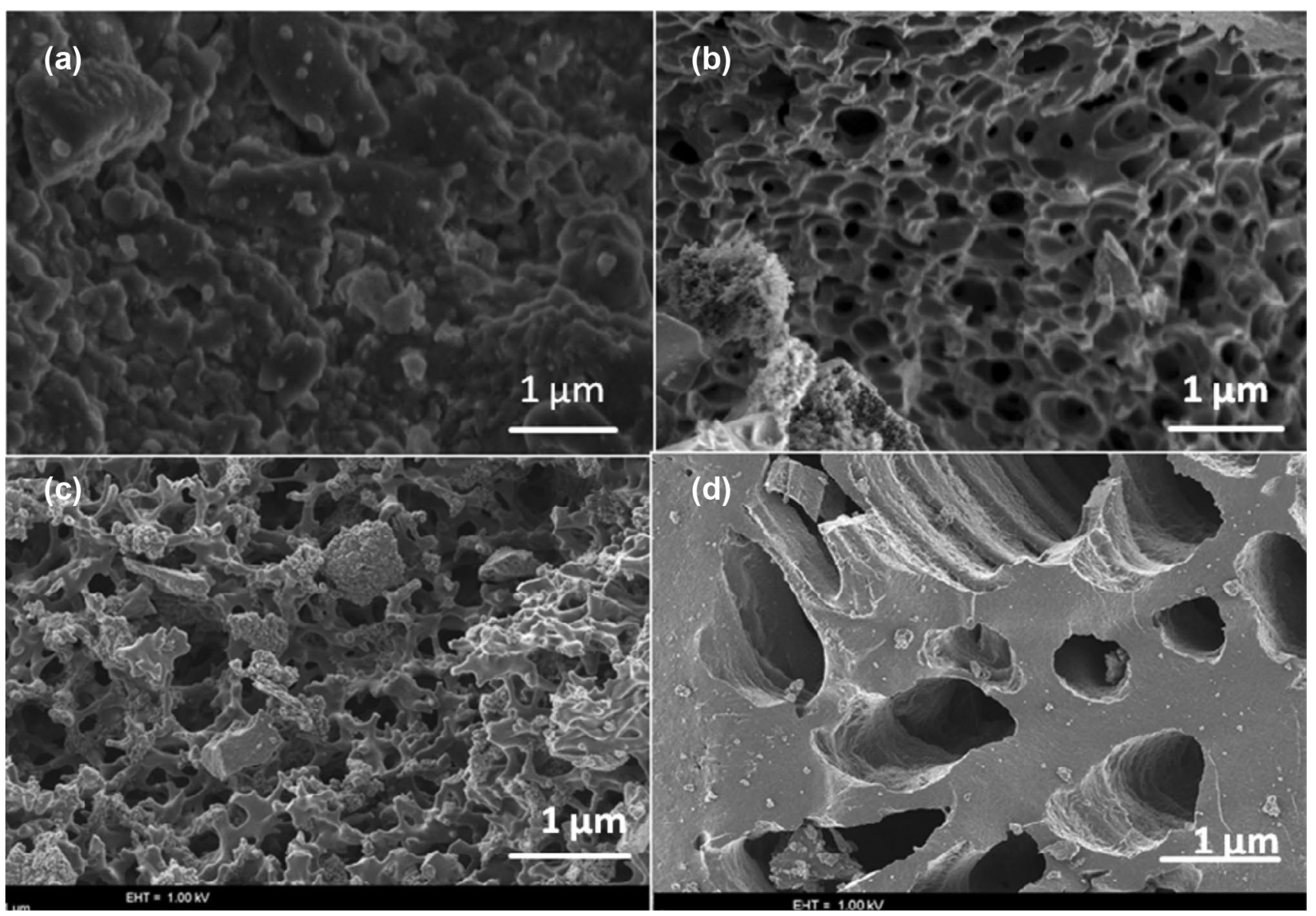

Fig. 3 SEM micrographs of a VM, b VM600, c VM700 and d VM800 

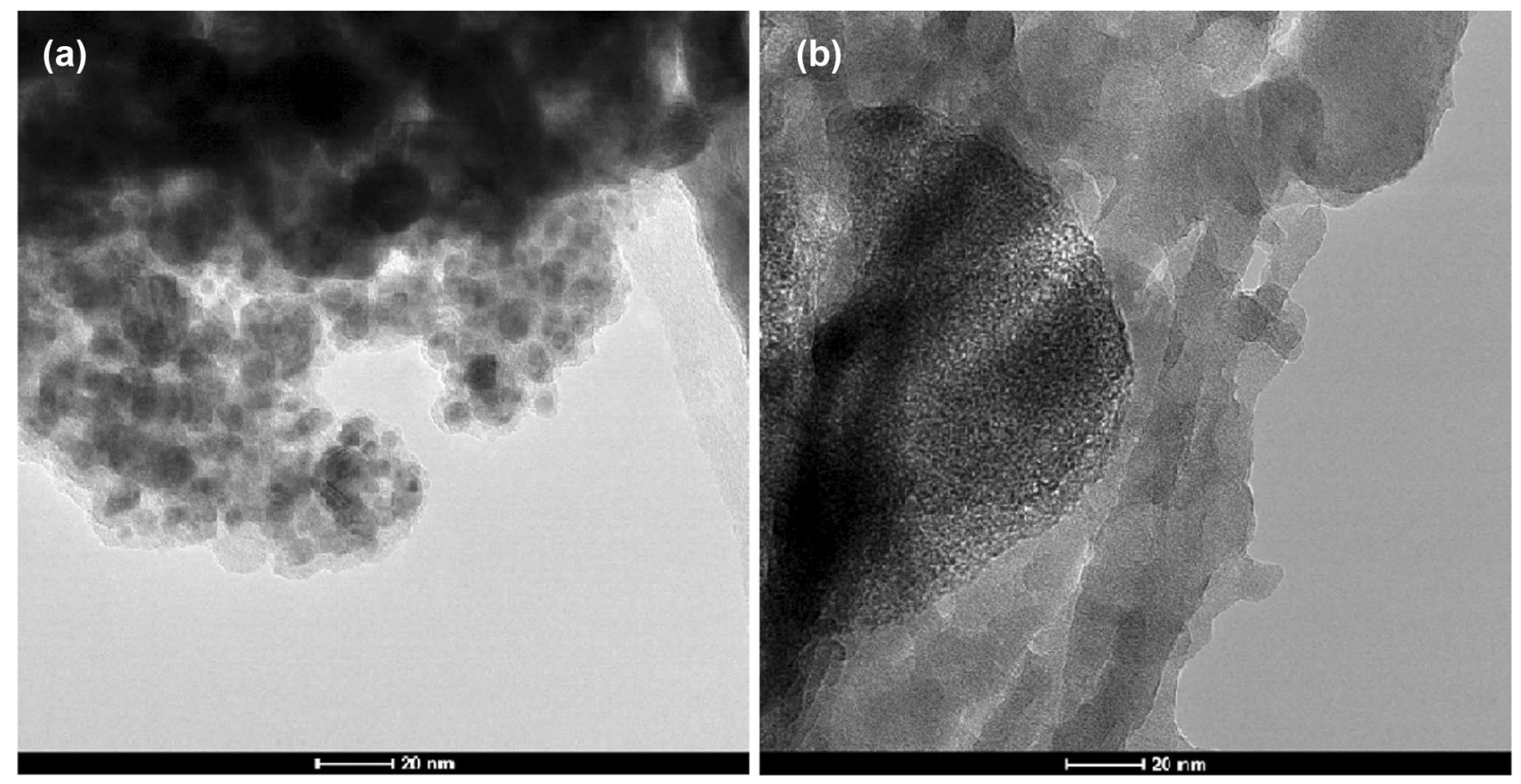

Fig. 4 TEM images of a VM and b VM 700

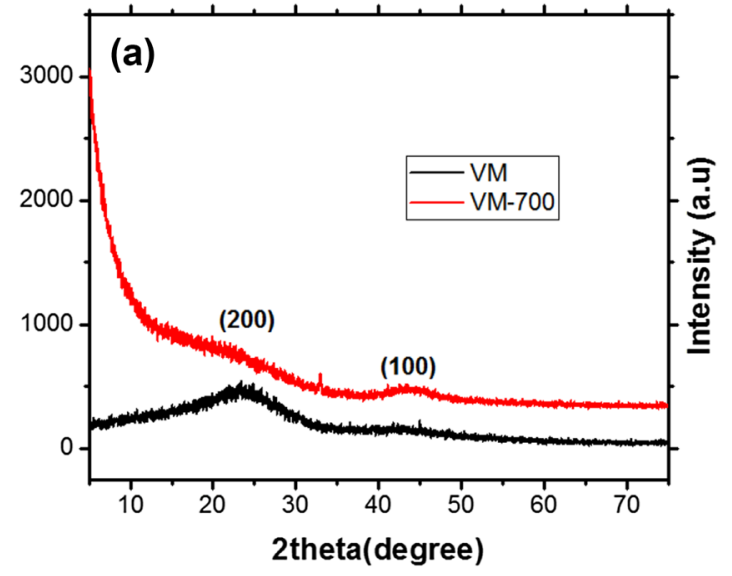

Fig. 5 a XRD patterns of VM and VM700, b Raman spectrum of VM700

were embedded in the carbon framework which in turn disturbed the lattice periodicity, thus reducing the peak of the plane indexed to $(200)[28,29]$. The structure of the VM700 as representative sample was further investigated through Raman analysis. Figure $5 \mathrm{~b}$ depicts two carbon materials prominent peaks located at 1348 and $1602 \mathrm{~cm}^{-1}$ which correspond to $D$ and $G$ bands. It is worth to note that $D$ peak is due to disordered carbon structure while $\mathrm{G}$ band represents the $s p^{2}$ hybridization graphitic carbon [30]. The ratio of intensity of the $D$ band to that of $G$ band $\left(I_{D} / I_{G}\right)$ of VM700 was about 0.84 which indicates the graphitization of the synthesized sample.

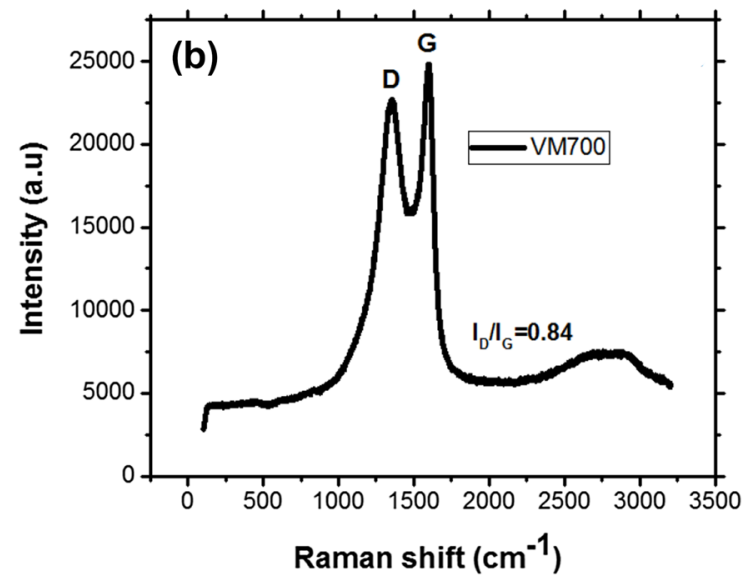

As shown in Fig. 6, X-ray photoelectron spectroscopy was used to investigate the surface chemistry of the synthesized materials. XPS survey spectra of VM and VM700 as representative samples are shown in Fig. 6 a. It can be pointed out the samples contained $\mathrm{C} 1 \mathrm{~s}, \mathrm{O} 1 \mathrm{~s}$ CKLL and O KLL core level peaks with main peaks at 284, 400 and $532 \mathrm{eV}$ which correspond to multiple coexistence of $\mathrm{CO}$ and $\mathrm{N}$, respectively [31]. One can see that carbon is the main component in the materials followed by oxygen with small content of $\mathrm{N}$ in $\mathrm{VM}$; however, the content of $\mathrm{N}$ was negligible for $\mathrm{VM} 700$, indicating that the $\mathrm{KOH}$ activation influences the $\mathrm{N}$ content. The 

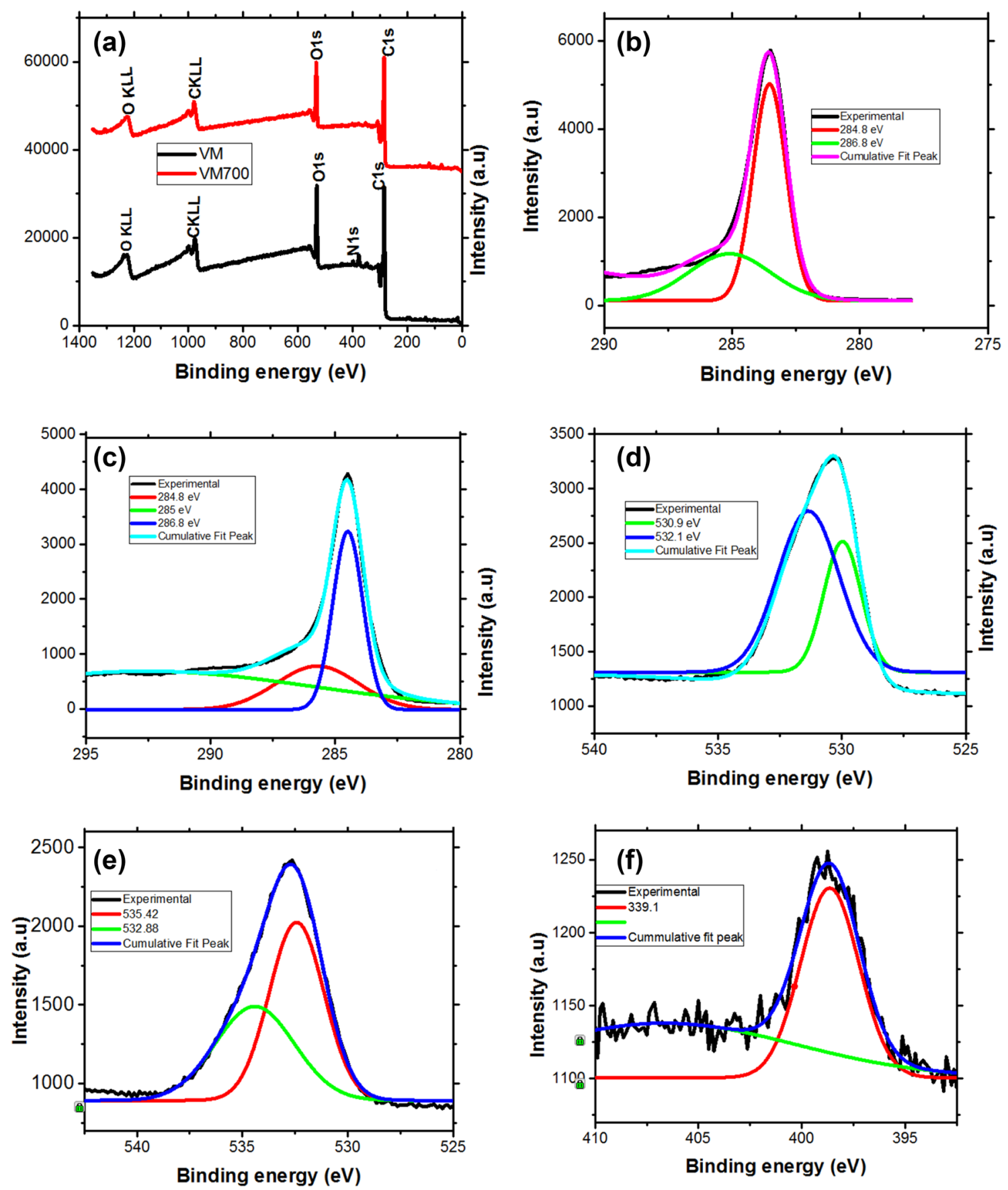

Fig. 6 XPS results. a Survey spectra for VM and VM700, b C1s deconvolution of VM, c C1s deconvolution of VM700, d O1s deconvolution of $\mathrm{VM}, \mathbf{e} \mathrm{O} 1 \mathrm{~s}$ deconvolution of VM700 and N1s deconvolution of VM

presence of oxygen groups and nitrogen groups in the synthesized samples confirms that the porous materials were self-doped. Furthermore, these results are consistent well with $\mathrm{CHNO}$ s results. C1s spectra for VM and VM700 were deconvoluted into two main peaks at 284.8 and $286.8 \mathrm{eV}$ for epoxy and alkoxy, respectively. The $\mathrm{O} 1 \mathrm{~s}$ was further deconvoluted into two oxygen-containing functional groups. These groups include $\mathrm{C}=\mathrm{O}(531 \mathrm{eV})$ and $\mathrm{C}-\mathrm{O}(532.1 \mathrm{eV})$ for VM sample while VM700 was deconvoluted into $533 \mathrm{eV}, 535.4 \mathrm{eV}$. N1s spectra of VM were deconvoluted into only one type (a pyridinic) which corresponded to $399.1 \mathrm{eV}$. It is assumed that pyridinic nitrogen species contribute to pseudocapacitance $[14,32]$. 


\subsection{Electrochemical performances}

In order to assess the effectiveness of the synthesized materials for supercapacitor electrodes cyclic voltammetry (CV) and electrochemical impedance spectroscopy (EIS) were carried out. Figure 7 shows the voltammograms of the fabricated electrodes VM, VM600, VM700 and VM800. It can be seen that all voltammograms acquired the quasirectangular shape in the voltage window of -1 to $0 \mathrm{~V}$. This is an indication that the fabricated electrodes had EDL characteristics. The area under the CV curves increased with activation temperature Fig. 7b, $c$ and then dropped at high temperature (Fig. 7d). There were some small eversible bumps in the CV curves (Fig. 7a-d), and these may have been attributed by the presence of heteroatoms functional groups in the synthesized porous materials as confirmed by XPS results.

Figure 8a shows the specific capacitance of the electrode as calculated from CV curves. It is shown the activation temperature leads to dramatic increase in specific capacitance from 118 to 402,437 and $377 \mathrm{~F} \mathrm{~g}^{-1}$ for VM, VM600, VM700 and VM800, respectively, at a scan rate of $5 \mathrm{mV} \mathrm{s}^{-1}$. VM700 attained the highest specific capacitance which could have been attributed to its high BET surface area as well as high micropore content. The higher surface area creates large sites to be accessed by ions. The specific capacitance obtained in this study $\left(437 \mathrm{~F} \mathrm{~g}^{-1}\right)$ was higher than that for mesoporous carbon derived from fullerene crystals $\left(286 \mathrm{~F} \mathrm{~g}^{-1}\right.$ ) [33], Metaplexis $\left(256.5 \mathrm{~F} \mathrm{~g}^{-1}\right)$ [34], biogas slurry $\left(289 \mathrm{~F} \mathrm{~g}^{-1}\right)$ [4] and coconut shell $\left(228 \mathrm{~F} \mathrm{~g}^{-1}\right)$ [35] at a scan rate of $5 \mathrm{mV} \mathrm{s}^{-1}$. The results presented in Fig. $8 \mathrm{~b}$ suggest that there is close relationship between the BET surface area, $\left(S_{\text {micro }} / S_{\text {meso }}\right),\left(V_{\text {micro }} / V_{\text {meso }}\right)$ and specific capacitance exhibited by the electrodes. One can see in Fig. $8 \mathrm{~b}$ that $\mathrm{VM}$ had the highest $\left(S_{\text {micro }} / S_{\text {meso }}\right),\left(V_{\text {micro }} / V_{\text {meso }}\right)$, BET surface area and so was the specific capacitance implying that pore textures influence the electrochemical performances of electrodes.

Figure $8 \mathrm{c}$ shows the electrochemical impedance spectroscopy (EIS) of fabricated electrodes. It is revealed from Nyquist (a)

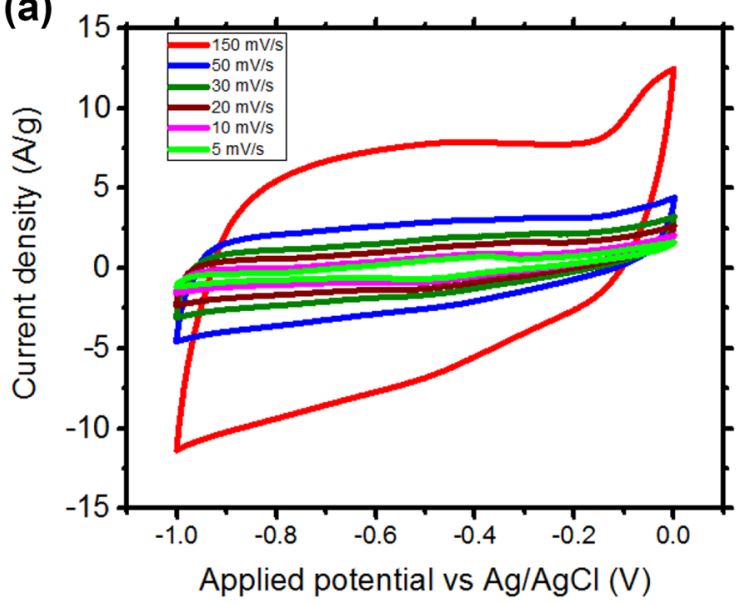

(c)

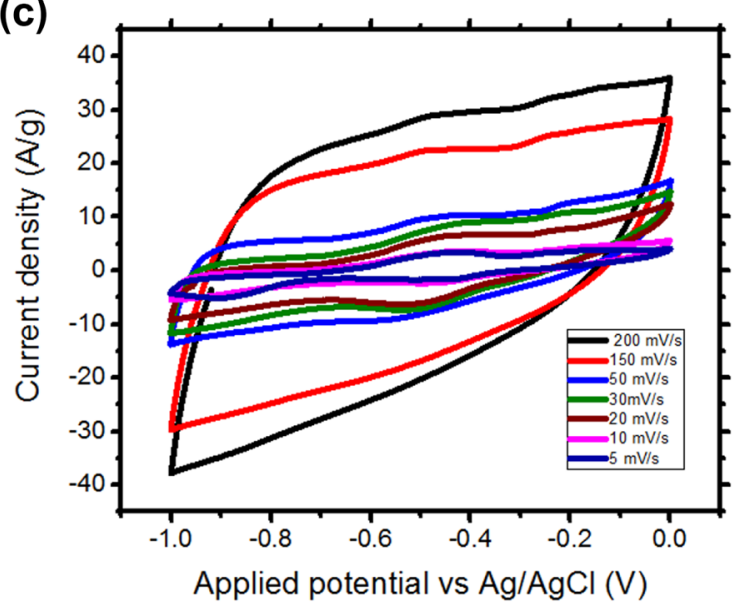

(b)

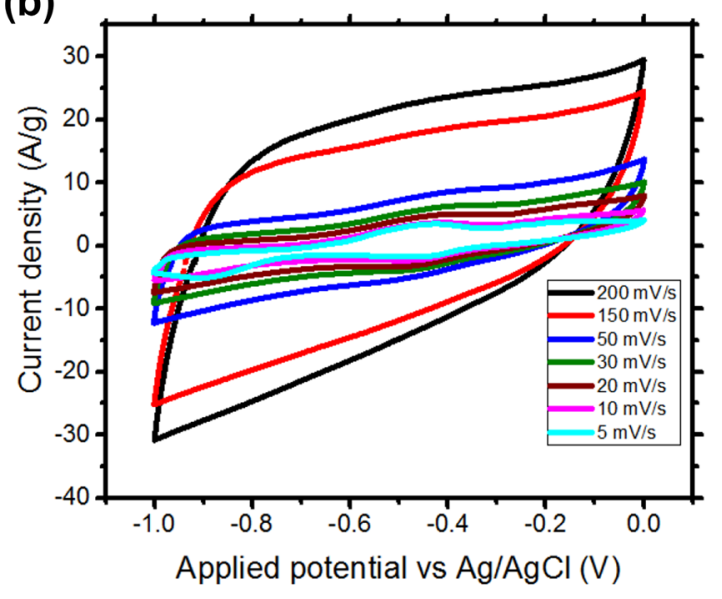

(d)

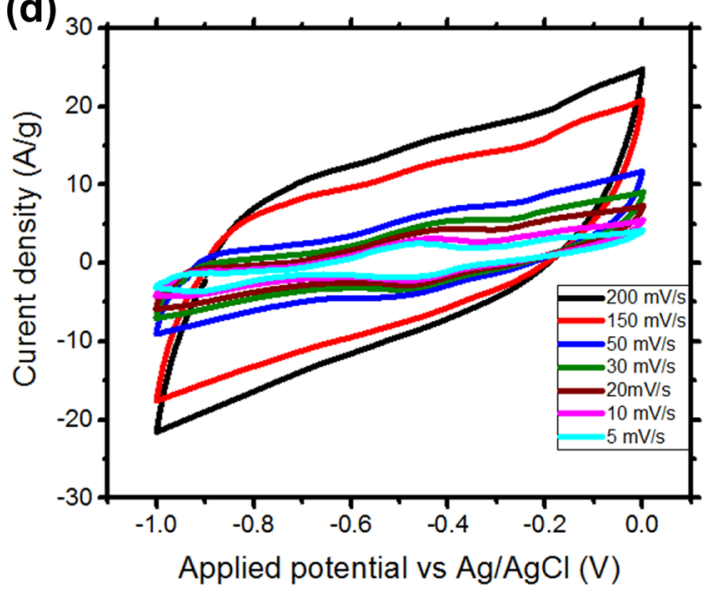

Fig. 7 Cyclic voltammograms of a VM, b VM600, c VM700, d VM800 


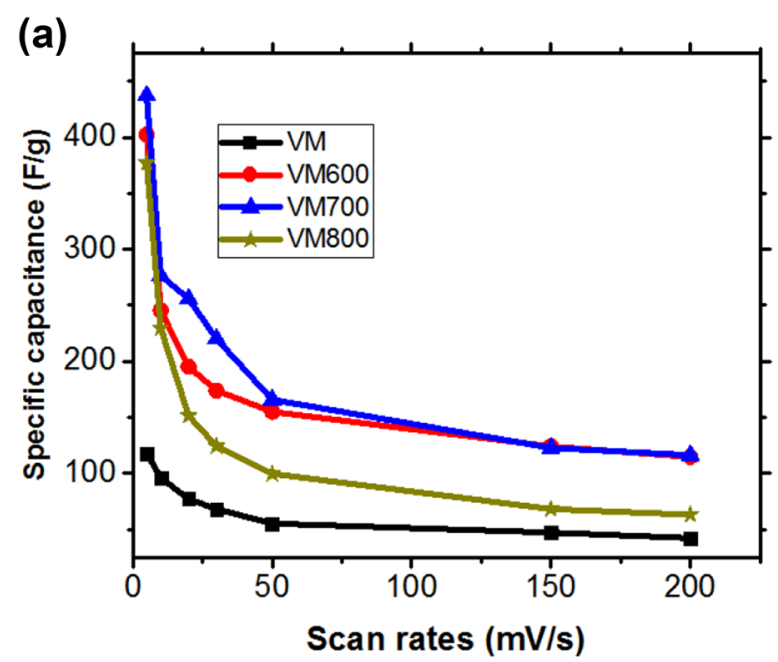

(b)
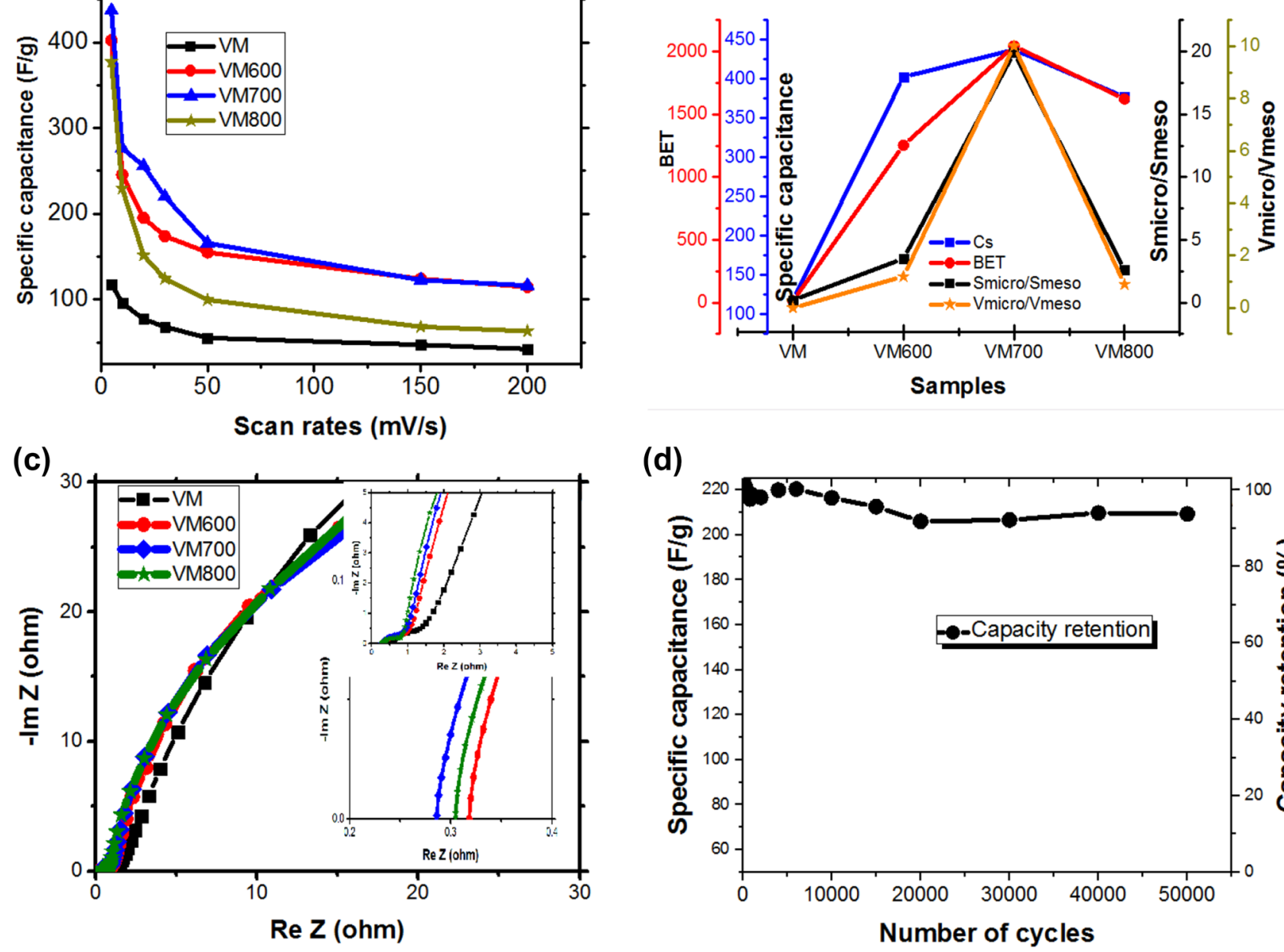

(d)

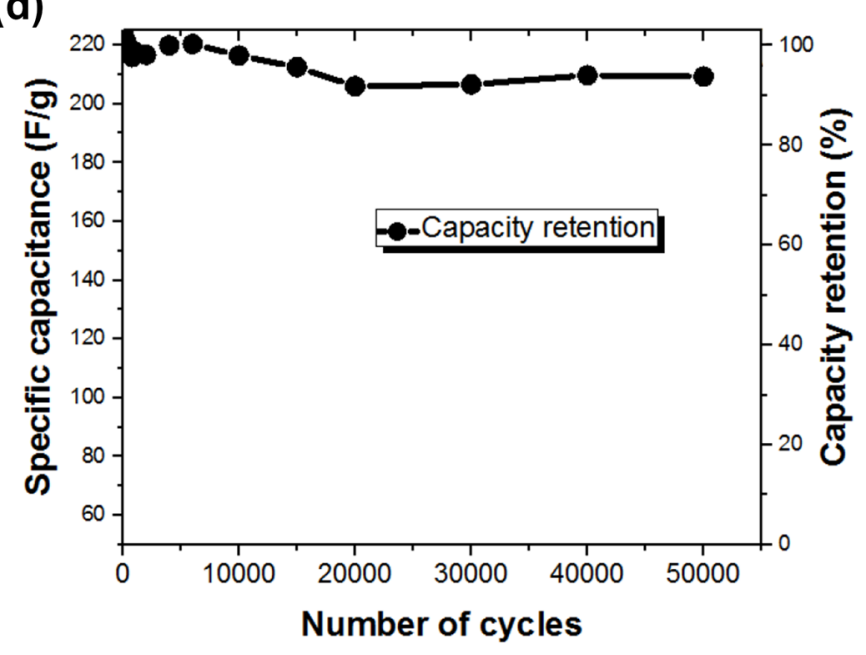

Fig. 8 a Specific capacitances, b relationship between pore textures and specific capacitance, c Nyquist plots, d cyclic stability

plot that all the synthesized carbon materials exhibited high ionic conductivity and the intercepts with horizontal axis of VM 600, VM700 and VM800 electrodes were between 2.5 and $3.5 \Omega$ (see the insert of Fig. $8 \mathrm{c}$ ). The internal resistances were $0.29,0.31$ and $0.32 \Omega$ for VM600, VM700 and VM800, respectively. The smaller semicircle with vertical line at the lower frequency existed for all samples which implied that the electrodes had low charge transfer resistance at the electrode/electrolyte interface; thus, there was fast electrolyte ion diffusion into mesopores. Additionally, the supercapacitor electrode (VM700) demonstrates high cyclic stability with capacitance retention of over $90 \%$ after 50,000 cycles which qualifies the materials for supercapacitor application.

\section{Conclusion}

In summary, highly porous carbon nanomaterials were synthesized by carbonizing Vitex mombassae (VM) seeds followed by subsequent activation. The effect of activation temperature $(600-800 \mathrm{C})$ on the textural microstructure and specific capacitances was studied. Highly porous carbon materials were synthesized with high specific surface area. The specific surface area increased with activation temperature and then dropped at higher temperature. On the other hand, the total pore volume increased with activation temperature. The resulting 
VM seeds possess unique porous surface structure with pore volume increasing from 0.8 to $1.1 \mathrm{~cm}^{3} \mathrm{~g}^{-1}$. Moreover, the optimized VM700 have a high BET specific area $\left(2043.8 \mathrm{~m}^{2} \mathrm{~g}^{-1}\right)$, high micropore surface area (95\%) and micropore pore volume (89\%) which facilitates the electrochemical double-layer capacitance. Due to these advantages, the VM700 exhibit a high specific capacitance of $437 \mathrm{~F} \mathrm{~g}^{-1}$ at a scan rate of $5 \mathrm{mV} \mathrm{s}^{-1}$ in $6 \mathrm{M} \mathrm{KOH}$ electrolyte. More importantly, the electrodes exhibited over $90 \%$ capacity retention after 50,000 cycles, indicating that VM-based porous materials are promising electrode materials for supercapacitors.

Acknowledgements This work was supported by the Government of Tanzania through Mkwawa University College of Education. University of Connecticut, USA, is acknowledged for characterizing the samples.

\section{Compliance with ethical standards}

Conflict of interest There are no conflicts to declare.

\section{References}

1. Zhang S, Zhu J, Qing Y, Wang L, Zhao J, Li J, Tian W, Jia D, Fan Z (2018) Ultramicroporous carbons puzzled by graphene quantum dots: integrated high gravimetric, volumetric, and areal capacitances for supercapacitors. Adv Funct Mater 28(52):1805898

2. Sharma K, Arora A, Tripathi S (2019) Review of supercapacitors: materials and devices. J Energy Storage 21:801-825

3. Han J, Li Q, Wang J, Ye J, Fu G, Zhai L, Zhu Y (2018) Heteroatoms $(\mathrm{O}, \mathrm{N})$-doped porous carbon derived from bamboo shoots shells for high performance supercapacitors. J Mater Sci Mater Electron 29(24):1-11

4. Enock TK, King'ondu CK, Pogrebnoi A, Jande YAC (2017) Biogasslurry derived mesoporous carbon for supercapacitor applications. Mater Today Energy 5:126-137

5. Wei Q-L, Chen Z-M, Wang X-F, Yang X-M, Wang Z-C (2018) A twostep method for the preparation of high performance corncobbased activated carbons as supercapacitor electrodes using ammonium chloride as a pore forming additive. New Carbon Mater 33:402-408

6. Ahmed S, Rafat M, Ahmed A (2018) Nitrogen doped activated carbon derived from orange peel for supercapacitor application. Adv Nat Sci Nanosci Nanotechnol 9:035008

7. Parveen N, Al-Jaafari Al, Han Jl (2018) Robust cyclic stability and high-rate asymmetric supercapacitor based on orange peel-derived nitrogen-doped porous carbon and intercrossed interlinked urchin-like $\mathrm{NiCO}_{2} \mathrm{O}_{4} @ 3 \mathrm{DNF}$ framework. Electrochim Acta 293:84-96

8. Wang C, Xiong Y, Wang H, Sun Q (2018) All-round utilization of biomass derived all-solid-state asymmetric carbon-based supercapacitor. J Colloid Interface Sci 528:349-359

9. Enock TK, King'ondu CK, Pogrebnoi A (2018) Effect of biogasslurry pyrolysis temperature on specific capacitance. Mater Today Proc 5:10611-10620

10. Jin H, Li J, Yuan Y, Wang J, Lu J, Wang S (2018) Recent progress in biomass-derived electrode materials for high volumetric performance supercapacitors. Adv Energy Mater 8:1801007
11. Wang $H, X u Z$ Z, Kohandehghan A, Li Z, Cui K, Tan X, Stephenson TJ, Kingondu CK, Holt CM, Olsen BC (2013) Interconnected carbon nanosheets derived from hemp for ultrafast supercapacitors with high energy. ACS Nano 7(6):5131-5141

12. Wang Y, Yang R, Li M, Zhao Z (2015) Hydrothermal preparation of highly porous carbon spheres from hemp (Cannabis sativa $L$ ) stem hemicellulose for use in energy-related applications. Ind Crops Prod 65:216-226

13. Hu B, Wang K, Wu L, Yu SH, Antonietti M, Titirici MM (2010) Engineering carbon materials from the hydrothermal carbonization process of biomass. Adv Mater 22:813-828

14. Lin G, Ma R, Zhou Y, Liu Q, Dong X, Wang J (2018) KOH activation of biomass-derived nitrogen-doped carbons for supercapacitor and electrocatalytic oxygen reduction. Electrochim Acta 261:49-57

15. Sevilla M, Diez N, Ferrero GA, Fuertes AB (2019) Sustainable supercapacitor electrodes produced by the activation of biomass with sodium thiosulfate. Energy Storage Mater 18:356-365

16. Zhang G, Chen Y, Chen Y, Guo H (2018) Activated biomass carbon made from bamboo as electrode material for supercapacitors. Mater Res Bull 102:391-398

17. Zou K, Deng Y, Chen J, Qian Y, Yang Y, Li Y, Chen G (2018) Hierarchically porous nitrogen-doped carbon derived from the activation of agriculture waste by potassium hydroxide and urea for high-performance supercapacitors. J Power Sour 378:579-588

18. Yu D, Ma Y, Chen M, Dong X (2019) KOH activation of wax gourdderived carbon materials with high porosity and heteroatom content for aqueous or all-solid-state supercapacitors. J Colloid Interface Sci 537:569-578

19. Song Y, Li W, Xu Z, Ma C, Liu Y, Xu M, Wu X, Liu S (2019) Hierarchical porous carbon spheres derived from larch sawdust via spray pyrolysis and soft-templating method for supercapacitors. SN Appl Sci 1:122

20. Joseph S, Kempaiah DM, Benzigar MR, Ilbeygi H, Singh G, Talapaneni SN, Park D-H, Vinu A (2019) Highly ordered mesoporous carbons with high specific surface area from carbonated soft drink for supercapacitor application. Microporous Mesoporous Mater 280:337-346

21. Kraiwattanawong $\mathrm{K}$ (2019) Improvement of the textural properties of templated carbon xerogels using cotton fibres as a hard template dehydrated by sulphuric acid. Diam Relat Mater 92:9-17

22. Yin Y, Gao Y, Zhang Y, Li A, Ji G (2019) Synthesis of honeycomblike hierarchical porous carbon via molten salt pyrolysis in a novel sequencing integration system for high-performance supercapacitors. Microporous Mesoporous Mater 278:195-205

23. Li J, Tian L, Liang F, Wang J, Han L, Zhang J, Ge S, Dong L, Zhang $\mathrm{H}$, Zhang S (2019) Molten salt synthesis of hierarchical porous $\mathrm{N}$-doped carbon submicrospheres for multifunctional applications: high performance supercapacitor, dye removal and $\mathrm{CO}_{2}$ capture. Carbon 141:739-747

24. Lu X, Zhang Y, Zhong H, Yang L, Xu X, Liu H, Yuan C (2019) Molten-salt strategy for fabrication of hierarchical porous $\mathrm{N}$-doped carbon nanosheets towards high-performance supercapacitors. Mater Chem Phys 230:178-186

25. Minae S, Sambo E, Munthali S, Ng'ong'ola D (1995) Selecting priority indigenous fruit-tree species for central Malawi using farmers' evaluation criteria. In: Conference on the improvement of indigenous fruit trees of the Miombo woodlands of Southern Africa. Mangochi (Malawi)

26. Zhang S, Zhang Q, Zhu S, Zhang H, Liu X (2019) Porous Carbons Derived from desilication treatment and mixed alkali activation of rice husk char for supercapacitors. In: Energy sources, part A: recovery, utilization, and environmental effects, pp 1-9

27. Lua AC, Yang T (2004) Effect of activation temperature on the textural and chemical properties of potassium hydroxide 
activated carbon prepared from pistachio-nut shell. J Colloid Interface Sci 274:594-601

28. Chang J, Gao Z, Zhao W, Guo L, Tang Y, Wu D, Xu F, Jiang K (2016) Nitrogen doped microporous carbons with tunable and selective performances in supercapacitor and heterogeneous catalysis. Electrochim Acta 190:912-922

29. Chang J, Gao Z, Liu X, Wu D, Xu F, Guo Y, Guo Y, Jiang K (2016) Hierarchically porous carbons with graphene incorporation for efficient supercapacitors. Electrochim Acta 213:382-392

30. Lu C, Huang YH, Wu YJ, Li J, Cheng JP (2018) Camellia pollenderived carbon for supercapacitor electrode material. J Power Sour 394:9-16

31. Wang C, Wang J, Wu W, Qian J, Song S, Yue Z (2019) Feasibility of activated carbon derived from anaerobic digester residues for supercapacitors. J Power Sour 412:683-688

32. Chen H, Chen J, Chen D, Wei H, Liu P, Wei W, Lin H, Han S (2019) Nitrogen-and oxygen-rich dual-decorated carbon materials with porosity for high-performance supercapacitors. J Mater Sci 54:5625-5640
33. Bairi P, Maji S, Hill JP, Kim JH, Ariga K, Shrestha LK (2019) Mesoporous carbon cubes derived from fullerene crystals as a high rate performance electrode material for supercapacitors. J Mater Chem A 7(20):12654-12660

34. Liang C, Bao J, Li C, Huang H, Chen C, Lou Y, Lu H, Lin H, Shi Z, Feng $S$ (2017) One-dimensional hierarchically porous carbon from biomass with high capacitance as supercapacitor materials. Microporous Mesoporous Mater 251:77-82

35. Mi J, Wang X-R, Fan R-J, Qu W-H, Li W-C (2012) Coconut-shellbased porous carbons with a tunable micro/mesopore ratio for high-performance supercapacitors. Energy Fuels 26:5321-5329

Publisher's Note Springer Nature remains neutral with regard to jurisdictional claims in published maps and institutional affiliations. 